\title{
Single-port retroperitoneal renal biopsy using standard urological instruments
}

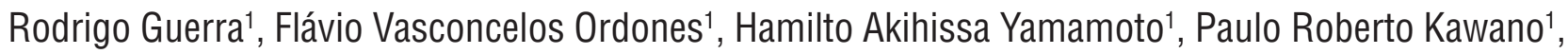 \\ João Luiz Amaro ${ }^{1}$ \\ ${ }^{1}$ Department of Urology, Medical School, São Paulo State University (UNESP), Botucatu, SP, Brazil
}

\section{ABSTRACT}

Objective: To describe the surgical technique and initial experience with a single-port retroperitoneal renal biopsy (SPRRB).

Materials and Methods: Between January and April 2013, five children underwent SPRRB in our hospital. A single $1.5 \mathrm{~cm}$ incision was performed under the 12 th rib at mid-axillary line, and an $11 \mathrm{~mm}$ trocar was inserted. A nephroscope was used to identify the kidney and dissect the perirenal fat. After lower pole exposure, a laparoscopic biopsy forceps was introduced through the nephroscope working channel to collect a renal tissue sample.

Results: SPRRB was successfully performed in five children. The mean operative time was 32 minutes, and mean estimated blood loss was less than $10 \mathrm{~mL}$. The hospital stay of all patients was two days because they were discharged in the second postoperative day, after remaining at strict bed rest for 24 hours after the procedure. The average number of glomeruli present in the specimen was 31 .

Conclusion: SPRRB is a simple, safe and reliable alternative to open and videolaparoscopic approaches to surgical renal biopsy.

\section{ARTICLE INFO}

\section{Key words:}

Kidney; Biopsy; Retroperitoneal Space; Surgical Procedures, Operative; Minimally Invasive Surgical Procedures; Laparoscopy

Int Braz J Urol. 2015; 41: 168-71

Submitted for publication: February 09, 2014

Accepted after revision:

May 13, 2014

\section{INTRODUCTION}

Image-guided percutaneous renal biopsy is the most widely used method to sample renal parenchyma for the evaluation of malignancy or diffuse renal disease. The risks of this procedure are minimal and the overall success rate of all renal biopsies varies from 70 to $100 \%$ (1). Its major indications rest on diagnosis and follow-up of several systemic and nephrological conditions that lead to glomerular damage and renal function impairment, providing useful data for treatment and prognosis. It may also be used for evaluation of solid renal masses and cystic renal lesions (1).
However, this method has absolute and relative contraindications that may hamper or preclude it, such as the presence of a solitary kidney, uncontrolled arterial hypertension, coagulation disorders, renal artery aneurysm, previous percutaneous needle biopsy failure and obesity. Bleeding and inadequate amounts of renal tissue for diagnosis are not infrequent, and constitute potential disadvantages of the procedure. In addition, children may be unable to cooperate, requiring general anesthesia.

In these settings, open and laparoscopic approaches are well-established alternatives and should be considered, although with a higher level 
of invasiveness and complexity. In search for an alternative that could minimize surgical aggressiveness of these procedures and hence spread its use, we outlined a renal biopsy technique through a single retroperitoneal laparoscopic access using standard urological instruments. The aim of this paper is to describe the technique now standardized in our institution and our initial experience with the Single Port Retroperitoneal Renal Biopsy (SPRRB).

\section{SURGICAL TECHNIQUE}

After receiving general anaesthesia, orogastric and bladder catheterization, the patient is usually positioned in the left flank position, as the kidney is more easily accessible at the right side due to its lower position. Standard preparation of the surgical field is performed. A $1.5 \mathrm{~cm}$ incision is carried out just below the tip of the 12th rib, at the mid-axillary line, and is followed by blunt access to the retroperitoneum space. An initial digital dissection is done aiming to identify the lower renal pole, while also displacing the peritoneum anteriorly. During this step, care must be taken in order to avoid peritoneal tearing, as the pneumoperitoneum resulting from gas insufflation would hamper the maintenance of adequate retroperitoneal working space. Next, a rubber balloon is positioned between the kidney and the posterior abdominal wall, and is filled with 300-400 cc of saline, creating a virtual cavity. The saline is drained after a few minutes, to achieve hemostasis, and the balloon is then removed. An $11 \mathrm{~mm}$ trocar is inserted and carbon dioxide is used to maintain pneumoretroperitoneum at 12 to $15 \mathrm{mmHg}$. Retroperitoneal inspection and identification of the psoas muscle and the lower pole of the kidney are now performed with a standard 26 French nephroscope, as shown in Figure-1. It is frequently possible to expose the renal surface bluntly, by using gentle movements of the tip of the scope to drag the perirenal fat away from the intended site of biopsy. Alternatively, standard laparoscopic surgical aspirator, scissors or hooks can be inserted through the working channel of the nephroscope, and then be used to dissect, cut and coagulate nearby structures, allowing a clear renal surface to be assessed. Once the biopsy site is cleared from fat, one or two samples are taken with the aid of a toothed biopsy forceps, also through the nephroscope (Figure-2). Bleeding is expected to be negligible, as the injury caused by the forceps is shallow (Figure-3), but the parenchyma can be coagulated with the same instruments, and a cellulose hemostatic bolster can be applied, if needed. Finally, the pneumoretroperitoneum is evacuated and, if no bleeding is observed, the trocar is removed and the access port is closed.

Figure 1 - Positioning of trocar and use of nephroscope for retroperitoneoscopy.

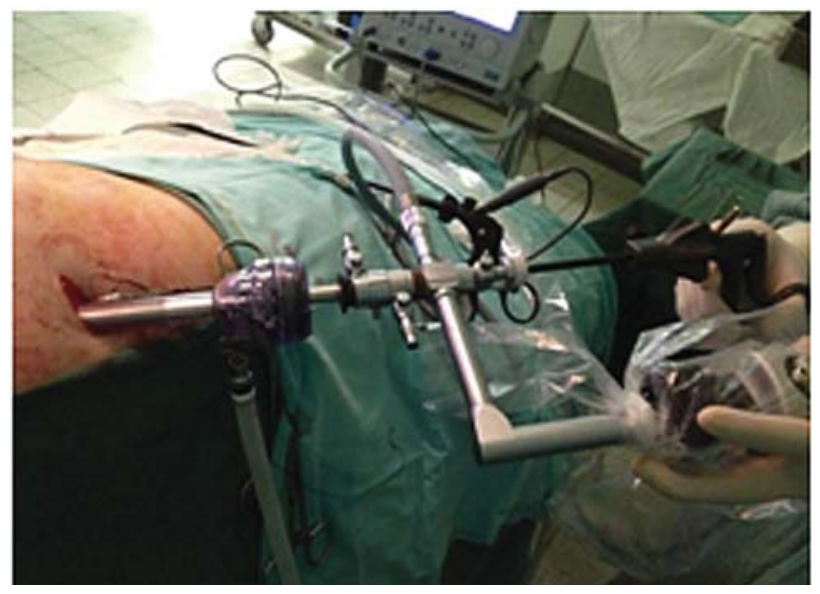

Figure 2 - Sampling renal parenchyma with a toothed biopsy forceps, through the nephroscope working channel.

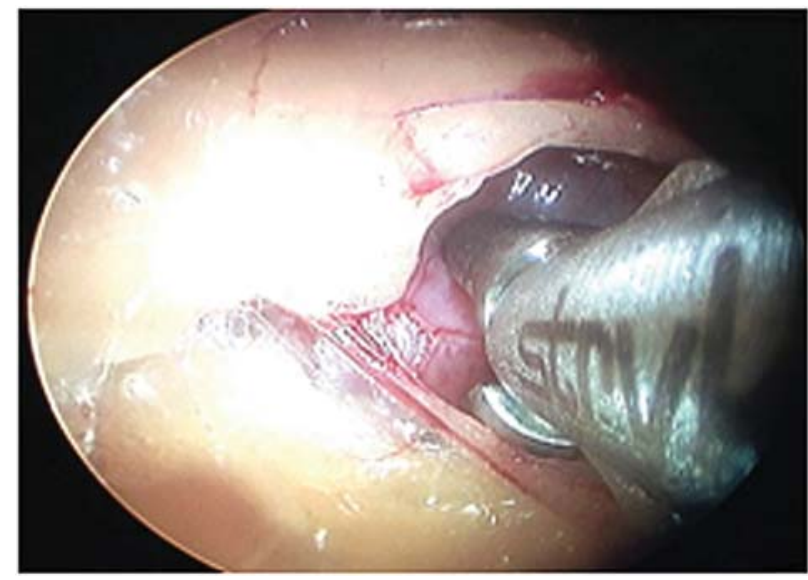


Figure 3 - Aspect of kidney surface after a tissue sample was taken, with only minimal bleeding.

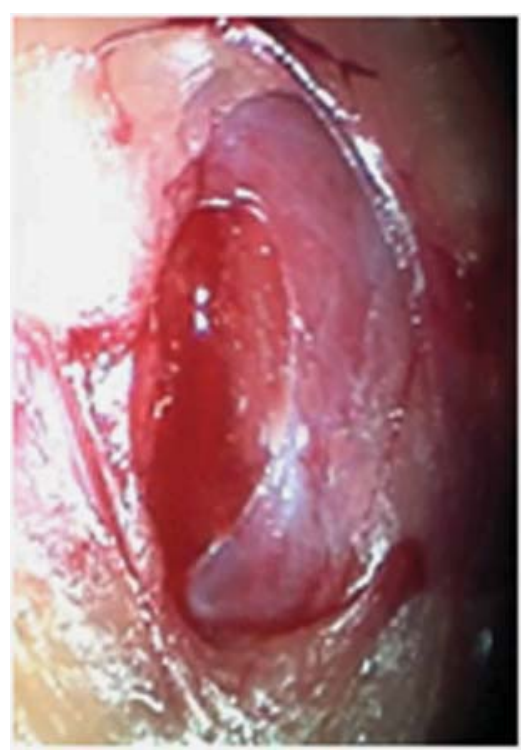

\section{COMMENTS}

At our institution, laparoscopic retroperitoneal renal biopsy is currently often performed for pediatric patients with nephrological conditions (2). As the surgical team's experience progressed and the procedure was standardized, however, we felt that it should be even less invasive, especially for this very young population. Additionally, in order to spread and popularize its execution, we devised how to use instruments that are already present in a regular urological operating room, such as the nephroscope and laparoscopic scissors and forceps, in a different fashion. A similar approach has been described previously, in pediatric surgery, for appendectomies and varicocelectomies, but with only one case of renal biopsy (3).

Between January and April/2013, five children underwent SPRRB in our hospital, referred from the Nephrology Clinic for renal biopsy. Informed consent was previously obtained from parents, respecting our institution's Ethics Committee recommendations and approval. Clinical characteristics of these patients are summarized in Table-1. In all cases, the procedure was successfully performed with the technique above des- cribed, by a supervised resident in-training. The overall mean operative time was 32 minutes, and mean estimated blood loss was less than $10 \mathrm{~mL}$. No open conversion was needed. The hospital stay of all patients was two days because they were kept in absolute bed rest for 24 hours after the procedure, before being discharged home. Pain and analgesics use were low, and there were no significant detected complications. Regarding the obtained samples, the average number of glomeruli present in the specimens was 31, and the histopathological findings showed focal proliferative lupus glomerulonephritis in two cases, diffuse mesangial proliferative glomerulonephritis in another two, and nephritis related to Henoch-Schönlein purpura in one child. These results are comparable to those previously shown by us, with laparoscopic renal biopsy in children, regarding operative time, blood loss, hospital stay and success in obtaining adequate samples (2).

Although it is likely that the same approach could be used in adult patients as well. Our experience with this very initial group was composed entirely of children, and SPRRB has been shown to be a very simple, safe and reliable alternative to other laparoscopic approaches. The use of a nephroscope, instead of a regular laparoscope, obviates the need to place an additional trocar for using an auxiliary instrument to dissect the perirenal fat, as is the standard practice $(4,5)$. Its working channel finely substitutes that, sparing one incision, the cost of another trocar and also surgical time to place it. Because a second trocar traditionally would be only $5 \mathrm{~mm}$ wide, it may seem that the benefit here is not strongly relevant in terms of postoperative pain or cosmetic results, but it is our understanding that no technical difficulty was added whatsoever, by using only one access. Moreover, especially children could benefit the most even of a small effect, and coincidently they constitute the majority of patients requiring a surgical renal biopsy in our hospital. Mini-perc nephroscopes are not available at our institution at this time, but its use could be a step forward, in this regard, and further decrease the required size of the access port incision. Additionally, the ease for urologists in using regular urological equipment, and the possibility that the surgeon simultaneously 
Table 1 - Clinical features of patients submitted to Single-port retroperitoneal renal biopsy.

\begin{tabular}{|c|c|c|c|c|c|c|c|c|}
\hline Patient & Gender & $\begin{array}{c}\text { Age } \\
\text { (years) }\end{array}$ & $\begin{array}{c}\text { BMI } \\
\left(\mathrm{Kg} / \mathrm{m}^{2}\right)\end{array}$ & $\begin{array}{c}\text { OT } \\
\text { (min.) }\end{array}$ & $\begin{array}{l}\mathrm{BL} \\
(\mathrm{mL})\end{array}$ & GN & Diagnosis & Complications \\
\hline 1 & M & 07 & 23.6 & 25 & 4 & 23 & $\begin{array}{l}\text { Diffuse mesangial } \\
\text { proliferative } \\
\text { glomerulonephritis }\end{array}$ & None \\
\hline 2 & $\mathrm{~F}$ & 09 & 24.5 & 37 & 13 & 38 & $\begin{array}{c}\text { Nephritis related to } \\
\text { Henoch-Schönlein } \\
\text { purpura }\end{array}$ & None \\
\hline 3 & $\mathrm{~F}$ & 11 & 21.8 & 27 & 5 & 30 & $\begin{array}{l}\text { Focal proliferative lupus } \\
\text { glomerulonephritis }\end{array}$ & None \\
\hline 4 & M & 10 & 24.0 & 40 & 17 & 43 & $\begin{array}{l}\text { Diffuse mesangial } \\
\text { proliferative } \\
\text { glomerulonephritis }\end{array}$ & $\begin{array}{l}\text { Small skin } \\
\text { ecchymosis }\end{array}$ \\
\hline 5 & $\mathrm{~F}$ & 12 & 32.0 & 31 & 6 & 21 & $\begin{array}{l}\text { Focal proliferative lupus } \\
\text { glomerulonephritis }\end{array}$ & None \\
\hline Average & - & 9.8 & 25.18 & 32 & 9 & 31 & - & - \\
\hline
\end{tabular}

$\mathbf{B M I}=$ Body mass index ( $\left.\mathrm{kg} / \mathrm{m}^{2}\right) ; \mathbf{O} \mathbf{T}=$ Operative time (minutes); $\mathbf{B L}=$ Blood loss (milliliters); $\mathbf{G N}=$ Number of glomeruli per biopsy.

controls both the camera and laparoscopic scissor/ biopsy forceps, are other advantages of this alternative method.

In our hospital, retroperitoneal laparoscopy is the procedure of choice for renal biopsy in children and the SPRRB is an even less invasive option for these patients, performed through a single incision and with very satisfactory results and only minor pain.

\section{ABBREVIATIONS}

SPRRB = Single Port Retroperitoneal Renal Biopsy

\section{CONFLICT OF INTEREST}

None declared.

\section{REFERENCES}

1. Uppot RN, Harisinghani MG, Gervais DA. Imaging-guided percutaneous renal biopsy: rationale and approach. AJR Am J Roentgenol. 2010; 194: 1443-9.
2. Jesus CM, Yamamoto H, Kawano PR, Otsuka R, Fugita OE. Retroperitoneoscopic renal biopsy in children. Int Braz J Urol. 2007; 33: 536-41; discussion 541-3

3. Martino A, Zamparelli M, Cobellis G, Mastroianni L, Amici G. One-trocar surgery: a less invasive videosurgical approach in childhood. J Pediatr Surg. 2001; 36: 811-4.

4. Luque Mialdea R, Martín-Crespo Izquierdo R, Díaz L, Fernández A, Morales D, Cebrían J. Renal biopsy through a retroperitoneoscopic approach: our experience in 53 pediatric patients. Arch Esp Urol. 2006; 59: 799-803.

5. Takeda M, Watanabe R, Kurumada S, Saito K, Tsutsui T, Takahashi K, et al. Endoscopic renal biopsy in pediatric patients: comparison of retroperitoneoscopy-assisted and retroperitoneoscopic methods. Nephron. 2000; 84: 199-200. 